\title{
A comparative study of stem cells between the mucosa of inferior turbinate and nasal polyps by nestin marker using immunhistochemical technique
}

\author{
Hatem A. Hatem, Nawfal K.Yas \&Shayma`a Jamal Ahmed,. \\ Anatomy department, College of Medicine, Baghdad University.
}

\begin{abstract}
Nasal polyps are mucosal lesions raised from paranasal sinuses as a response to infectious or inflammatory stimuli. From histological view, nasal polyps had thick and proliferative epithelial mucosa. Stem cells are originator cells; liable for regeneration of cells. Nestin is an intermediate filament protien expressed in progenitor cells and play a major role in tissue regeneration.

Nestin immunoreactive-positive cells (stem cells) was higher in mucosal epithelium of nasal polyp compare with mucosal epithelium of normal nasal inferior turbinate signify that stem cell may have specific role in nasal polyp formation.
\end{abstract}

\section{Introduction:}

Nasal polyps are mucosal lesions raised from paranasal sinuses as a response to infectious or inflammatory stimuli. They emerge as smooth, ,semi-translucent masses, usually originate in the middle meatus and ethmoid sinuses and influence $1 \%$ to $4 \%$ of the population (Tritt $\mathrm{S}$ et al., 2008).

From histological view, nasal polyps had thick and proliferative epithelial mucosa, hyperplasia of submucosal glands, thick basement membrane, and stromal edema with abundant blood vessels (Bateman ND et al., 2003).

Stem cells are originator cells; liable for regeneration of cells, and take part in tissue repair on a variety of mucosal surfaces (Randell SH., 2006).

Nestin is an intermediate filament protien expressed in progenitor cells and play a major role in tissue regeneration. Cell division requires that compartments of cytoplasm and nucleus exist disassembled, restructured and partitioned into offspring cells (Ehrmann J et al., 2005).

Many studies have introduced a diversity of stem cell markers with nestin (Kang MK et al., 2007).

Preceding studies had detect the proliferative activity of nasal polyp by using immunomarkers like PCNA and Ki67. PCNA was a nuclear protein which concerned with growth regulation. Ki67 was an antibody recognizes a nuclear antigen which found in all phases of mitotic divisions. PCNA and Ki67 immunolabeled cells were concentrated in the basal layer of the epithelium (Mumbuc $\mathrm{S}$ et al., 2007).

A new study investigates whether the stem cells which obtained from nasal epithelium of patients with nasal polyp are inherently different from those obtained from healthy controls. Stem cells of human nasal epithelium from controls were stained positively with stem cell marker KRT5 and p63 and existing a consistent high expression level of Ki67. on the contrary, stem cells of human nasal epithelium from patients with nasal polyp show feeble stained with stem cell marker KRT5and p63 and a lower proportion of Ki671 cells. So; the study suggests that reduced growth/proliferation dynamics in stem cells of human nasal epithelium from patients with nasal polyp might be a significant pathological phenomenon in growth of nasal polyp.(Yu X.M. et al., 2014).

Another new study investigated whether stem cells might alter phenotype of cell in the nasal polyp and supposes that stem cells possibly helpful adjunct used for exploration of the inflammatory process in nasal polyps (Rogério Pezato et al., 2014).

This study was planned to find any different in number of nestin -immunereactive stem cell between the epithelium of normal nasal mucosa and epithelium of nasal polyps and find if there is any role of stem cells in pathogenesis of nasal polyps.

\section{Sample collection}

\section{Patients and methods:}

(58) Patients undergoing nasal surgery were selected for this study from the Department of Otolaryngology, Gazi Al-Hariri Teaching Hospital ,Baghdad; Iraq from May 2013 to January 2014.they were divided as follows:

1. Control group: (22) Samples of mucosa of inferior turbinate were obtained from patients undergo turbinectomy intended for inferior turbinate hypertrophy, (16) of them were females and (6) were males as 
shown in table (1), all cases were in $20^{\text {th }}$ were used as normal controls in this study. The inferior turbinate mucosa was grossly normal, with no evidence of infection or inflammation.

2. Study group: (36) Samples of nasal polyposis were obtained from patients who had undergone nasal polypectomy, (22) females and (14) males, all cases were in $20^{\text {th }}$ age old except one female was 10 years old.

\section{Table(1): Sample groups}

\begin{tabular}{|c|c|c|c|c|c|}
\hline \multirow{2}{*}{ Group } & \multicolumn{2}{|c|}{ Females } & \multicolumn{2}{c|}{ Males } & \multirow{2}{*}{$\begin{array}{c}\text { Total } \\
\text { number }\end{array}$} \\
\cline { 2 - 5 } & Number & $\%$ & Number & $\%$ & 22 \\
\hline Control & 6 & 27.3 & 16 & 72.7 & 36 \\
\hline Study & 22 & 61 & 14 & 39 & \\
\hline
\end{tabular}

Immunohistochemical procedure:

Samples from both groups were immersed during the night in a newly prepared fixative containing $4 \%$ paraformaldehyde in phosphate-buffered saline (PBS, pH 7.4). Then samples were dehydrated in a graded series of ethanol to xylene and embedded in paraffin wax. Immunohistochemical staining was performed by a peroxidase-labeled streptavidin-biotin technique. In brief, paraffin sections $(4 \mathrm{~mm})$ were slice and sited on positive charged -glass slides. Then sections stained for nestin were putted in autoclave in $10 \mathrm{mM}$ citrate buffer (pH 6.0) for 5 min.

Sections were treated with $3 \% \mathrm{H} 2 \mathrm{O} 2$ in methanol for $15 \mathrm{~min}$ to gratify activity of endogenous peroxidase. After washing in PBS, incubation of sections were done during the night at 48C with a 1:500 dilution of anti-nestin antibody (abcam,USA)

\section{Scoring procedure:}

The positive cell mean the cell which contains nestin protein and looks brown in color owing to treatment with DAB solution. Other than, the cell which is negative i.e. doesn't have nestin protein and looks blue in color owing to counterstaining with hematoxillin solution. The nestin protein is restricted in the cytoplasm, thus the cytoplasm looks brown and nucleus looks blue. (Pai SA\& Patil PU, 2008).

Quantification of nestin protein expression was evaluated under light microscopy at X100, X400, and $\mathrm{X} 1000$. The counting of positive cells was performed at X1000. Immunohistochemistry was given percentage scores, based on the number of signals. Positive cells were counted in ten different fields of 100 cells for each sample and the average of positive cells of the ten fields was determined assigning cases to one of the three following score categories: $\operatorname{Score}(1)=1-25 \%, \operatorname{Score}(2)=26-50 \%$, Score(3)>50\% (Alizi S et al.,2012).

\section{Statistical analysis:}

Pearson Chi square was used to detect relation between stem cell score with the age \& gender(P value $>0.05$ in both variables).

Independent sample T-test was used for evaluation of significance of the stem cell score level between control \& nasal polyp cases $(\mathrm{P}$ value $=0.00)$.

\section{Results:}

There was no significant relation between stem cell count with the age $\&$ gender.

Evaluation of significance of the stem cell count between control \& nasal polyp cases shows highly significant relation $(\mathrm{P}$ value $=0.00)$ which means highly significant relation .

Nestin immunoreactive-positive cells (stem cells) were higher in nasal polyps than normal nasal mucosa indicate that stem cell may play important role in pathogenesis or formation of nasal polyp as shown in figures(1\&2)

\section{Discussion:}

Previous study suggest that nestin is candidate for stem cell marker in the epithelium of nasal mucosa, may possibly contribute to differentiation of tissue in the nasal epithelium and submucosal glands of normal mucosa, and may possibly have a significant role in formation of nasal polyps. The nestin has been recognized in a mixture of normal and inflammatory tissues, implicating this marker in regeneration of tissue . The study investigated the distribution of nestin in the nasal mucosa of normal inferior turbinate and nasal polyps, using immunohistochemistry. Nestin was restricted to the epithelium and submucosal glands of normal nasal mucosa and nasal polyps. The expression of nestin was limited to the cytoplasm .Nestin expression was strongest in the basal part of the epithelial layer, and weak in the upper part. In the submucosal glands, weak to strong expression was usually detected in the glandular acini. There was no considerable variation in the level of 
expression of nestin between epithelium of normal nasal mucosa and epithelium of nasal polyps. (T. H. Kim et al.,2009).

Our work agree with( T.H. Kim et al.,2009 ) in that Nestin was restricted to the basal layer of epithelium of normal nasal mucosa and nasal polyps. The nestin expression was restricted to the cytoplasm. In normal nasal mucosa and nasal polyps, nestin expression was strongest in the basal part of the epithelial layer. But disagree with same study which indicates that there was no considerable variation in the level of expression of nestin between epithelium of normal nasal mucosa and epithelium of nasal polyps. While our study indicates that there was highly significant difference in nestin immunereactive positive cells( stem cell) between nasal polyp and normal nasal mucosa.

In conclusion, this descriptive study compared the number of stem cells (nestin immunereactive positive cells) in nasal polyp and healthy nasal mucosa. Results showed highly significant increase in stem cell count between nasal polyp as compared to controls. This suggests that stem cell may possibly play a role in the pathogenesis of nasal polyp.

\section{References:}

[1] Bateman ND, Fahy C, Woolford TJ. Nasal polyps: Still more questions than answers.J Laryngol Otol 2003; 117: 1-9.

[2] Ehrmann J, Kola'r Z, Mokry J: Nestin as a diagnostic and prognostic marker: immunohistochemical analysis of its expression in different tumours. J Clin Pathol 2005, 58:222-223.

[3] Kang MK, Kim RH, Kim SJ, Yip FK, Shin KH, Dimri GP,et al. Elevated Bmi-1 expression is associated with dysplastic cell transformation during oral carcinogenesis and is required for cancer cell replication and survival. Br J Cancer2007;96:126-33.

[4] Mumbuc S, Karakok M, Baglam T, Karatas E, Durucu C, Kibar Y. Immunohistochemical analysis of PCNA, Ki67 and p53 in nasal polyposis and sinonasal inverted papilloma. J Int Med Res2007;35:237-41.

5] Pai SA, Patil PU. Immunohistochemistry: some more benefits. Natl Med J India2008; 21(2): 100-101.

[6] Randell SH.Airway epithelial stem cells and the pathophysiology of chronic obstructive pulmonary disease. Proc Am Thorac Soc2006;3:718-25

[7] Rogério Pezato, Danilo Cândido de Almeida, Thiago Freire Bezerra,et al. Immunoregulatory Effects of Bone Marrow-Derived Mesenchymal Stem Cells in the Nasal Polyp Microenvironment. Mediators of Inflammation 2014; 2014:11.

[8] Tritt S, McMain KC, Kountakis SE. Unilateral nasal polyposis: Clinical presentation and pathology.Am J Otolaryngol 2008;29(4): $230-2$.

[9] T. H. Kim, H. M. Lee, S.H .Lee, et al. Expression and distribution patterns of the stem cell marker, nestin, and the stem cell renewal factor, BMI-1, in normal human nasal mucosa and nasal polyps. Acta Oto-Laryngologica 2009; 129: 996 1001.

[10] Yu, X.M. et al. Reduced growth and proliferation dynamics of nasal epithelial stem/progenitor cells in nasal polyps in vitro. Sci. Rep.2014; 4: 4619.

[11] Alizi S, Mukhlis F, \& Abdul-Majeed B. Detection of Human papillomavirus in surface epithelial ovarian carcinoma using in situ hybridization technique. Fac Med Baghdad $2012 ; 54: 1$. 